\title{
Minimally Invasive Techniques and Hybrid Operations for Esophageal Cancer
}

\author{
Christoph Wullstein Hye-Yoen Ro-Papanikolaou Christoph Klingebiel Koray Ersahin \\ Rene Carolus
}

Department of General, Visceral and Minimal Invasive Surgery, HELIOS Hospital, Krefeld, Germany

\section{Keywords}

Esophagectomy · Laparoscopy · Video-assisted thoracic surgery, VATS · Minimally invasive surgery · Outcome

\section{Summary}

Background: Minimally invasive esophagectomy (MIE) is slowly gaining acceptance due to advantages in shortterm outcome. While evidence is slowly increasing, the discussion about MIE is still controversial. Methods: A literature review was performed to compare MIE with open esophagectomy (OE). Current studies are summarized in view of short- and long-term outcome as well as oncological accuracy. Results: The majority of studies show that MIE is associated with a significant reduction of pulmonary complications, blood loss, and shorter length of stay on the intensive care unit. Pulmonary complications are reduced by $14-65 \%$. MIE shows an improved quality of life 6 weeks after surgery. There is some evidence that the endoscopic reintervention rate may be higher after MIE than after OE. Mortality rates do not differ. Regarding oncological results, the rate of $\mathrm{R} 0$ resections is comparable between $\mathrm{MIE}$ and $\mathrm{OE}$, as is the number of retrieved lymph nodes. Long-term survival seems to be comparable. A few single center trials suggest oncological advantages of MIE over OE concerning the number of lymph nodes, R0 resection rate, and 1-year survival. Conclusion: Current evidence supports that MIE has advantages over OE in the short-term outcome. Oncological results are comparable to those achieved by OE. As a result, MIE has already been included in current guidelines for the treatment of esophageal cancer.

(c) 2015 S. Karger GmbH, Freiburg

\section{Introduction}

Surgical resection remains an inherent part in the therapy of esophageal cancer. Morbidity and mortality of esophageal resection decreased over the last 10-15 years but still remain substantial, and especially pulmonary complications are frequent and remain a crucial aspect [1-3].

While Birkmeyer et al. [4] reported a 30-day mortality of $21.8 \%$ in low-volume centers and of $5.6 \%$ in high-volume centers in the USA during the years 1994-1999, current rates are mainly reported to range below $5 \%[5,6]$.

One approach in reducing mortality and morbidity of esophagectomy may be the implementation of minimally invasive techniques that have been shown to be beneficial in short-term outcomes for a variety of operations.

\section{History of Minimally Invasive Esophagectomy}

Cuschieri et al. [7] were the first who reported on minimally invasive esophagectomy (MIE) in 5 patients in 1992. In this series the esophagus was mobilized by video-assisted thoracic surgery (VATS). This study was followed by a few reports on minimally invasive techniques in esophageal resection. Collard et al. (1993) [8] and McAnena et al. (1994) [9] also reported on throracoscopic resection while DePaula et al. [10] reported on laparoscopic transhiatal resection in 1995. The clinical results in these early reports were not conclusive, and McAnena et al. [9] concluded at that time that a widespread adoption of this technique could not be recommended.

In 2003, Luketich et al. [11] reported the first large series of MIE and showed an impressively low morbidity and mortality in 222 patients. 30-day mortality and the rate of pneumonia were 1.4 and $7.7 \%$ in this series, respectively [11]. The first report on MIE in prone position in a large patient cohort was published by Palanivelu

\section{KARGER \\ Fax +497614520714

PD Dr. med. Christoph Wullstein

Klinik für Allgemein-, Viszeral- und Minimal Invasive Chirurgie, HELIOS Klinikum Krefeld Lutherplatz 40, 47805 Krefeld, Germany

christoph.wullstein@helios-kliniken.de 
et al. [12]. Both 30-day mortality and the rate of pneumonia in 130 patients amounted to $1.54 \%$. Following these promising results, MIE subsequently gained a slowly increasing acceptance.

\section{Methods}

The results of MIE are reviewed by performing a literature survey in which current trials, meta-analyses, and reviews were included. The main topics of this review are safety of the procedure, short- as well as long-term outcome, and oncological accuracy.

\section{Technique of Minimally Invasive Esophagectomy}

The terminology of MIE is inconsistent. Usually, complete minimally invasive esophagectomies (cMIE) are included either in a thoracoabdominal fashion with a combination of laparoscopy and VATS or by means of transhiatal laparoscopic esophagectomies. Hybrid minimally invasive esophagectomies (HMIE) are also included. In HMIE, either the abdominal or the thoracic part of the operation is performed in a conventional open manner. The different operations subsumed under the term MIE are shown in figure 1.

The frequency of the different approaches was analyzed by Decker et al. [13] in their systematic review from 2009. At that time, transhiatal esophagectomy was performed in $21.8 \%$, cMIE in $30.7 \%$, HMIE with laparotomy and VATS in 37.4\%, HMIE with laparoscopy and thoracotomy in $7.4 \%$, and robotic esophagectomy in $2.7 \%$ [13].

In CMIE, the thoracic part of the operation may be performed either in left lateral decubitus position or in prone position (table 1). Because the use of VATS in left lateral decubitus position is widespread in thoracic surgery, it is also more often utilized during MIE. The first VATS in prone position in esophagectomy was reported by Cushieri et al. [14] in 1994.

Indication for surgery, the principles of oncolocical esophagectomy, and the operative extent of lymphadenectomy in MIE follow the same rules as in open esophagectomy (OE) (fig. 2-4). Reconstruction is usually performed by either intrathoracical or cervical esophagogastrostomy.

\section{Results}

\section{Short-Term Outcome}

Since the publication of the exceptionally low mortality and morbidity rates in 222 patients by Luketich et al. [11, 15] in 2003, cMIE is supposed to be capable of substantially reducing the morbidity of esophagectomy. The same group confirmed their initial result in 1,011 patients in 2012. The 30-day mortality in the later series was $1.68 \%$, and the combined 30-day and in-hospital mortality amounted to $2.8 \%[11,15]$. Pulmonary complications were reported for empyema (6\%) and acute respiratory distress syndrome (ARDS) in $3 \%$.
Minimal Invasive Esophagectomy (MIE)

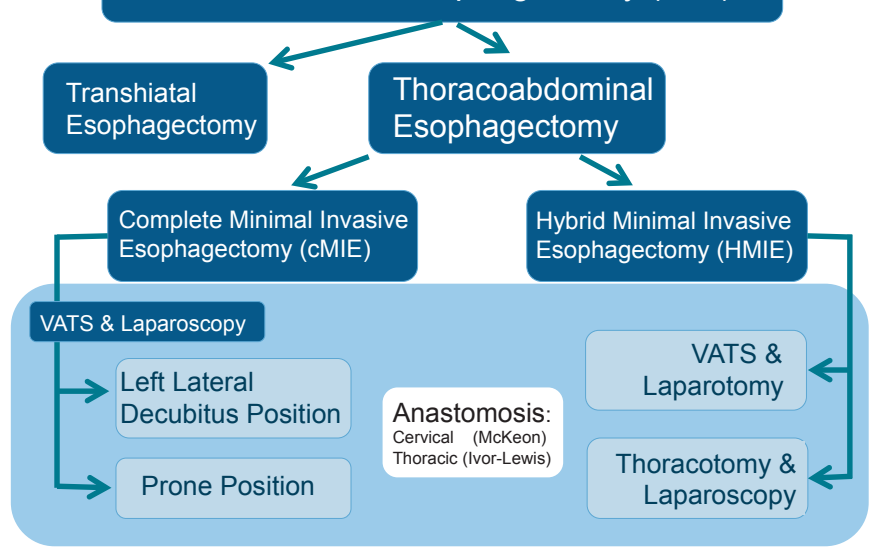

Fig. 1. Minimally invasive esophagectomy: subtypes.

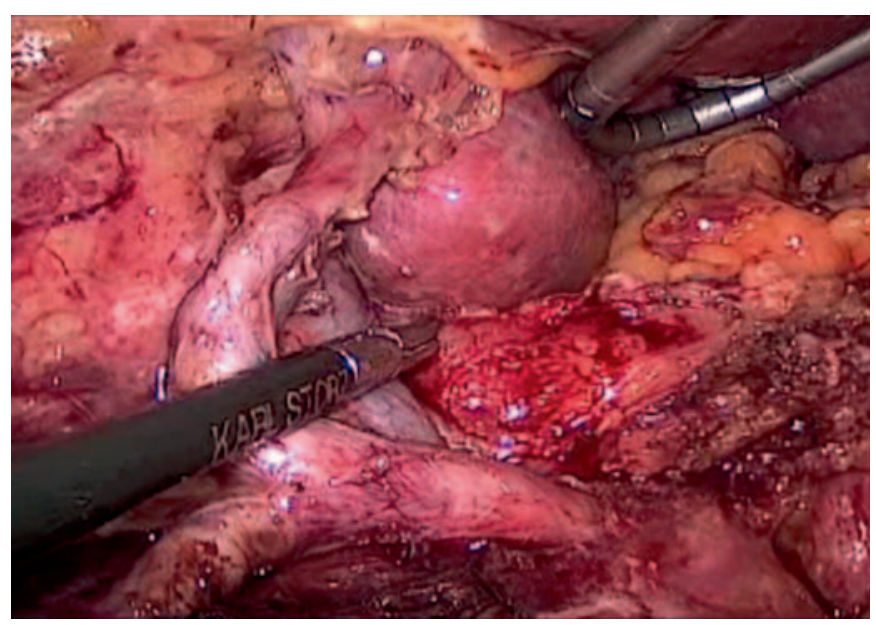

Fig. 2. Lymphadenectomy during laparoscopy in minimally invasive esophagectomy for distal adenocarcinoma.

The largest series with cMIE in prone position showed similar results. Palanivelu et al. [12] reported a 30-day mortality of $1.54 \%$ as well as major complications in $12.3 \%$ of the patients. Pneumonia was reported in $1.54 \%$.

The safety of cMIE was additionally proved by a recently published multicenter phase II trial from the USA. In this trial 17 centers performed 104 esophagectomies. 30-day mortality was $2.1 \%$. Pneumonitis and pulmonary infiltrates of grade 3 or higher were reported in 3.8\% and ARDS in 5.7\% [6].

Meanwhile, several single center reports including retrospective analyses comparing MIE with OE have been published. These publications have been analyzed in two systematic reviews and one meta-analysis $[13,16,17]$.

The systematic review by Verhage et al. [16] summarizes the results of ten case-controlled studies. In this review, MIE showed a reduction in blood loss by $45 \%$, a reduction of pulmonary complications by $34 \%$, and a reduction in the overall complication rate by $27 \%$. In this review, the number of retrieved lymph nodes was 23.8 in the minimally invasive group and 20.2 in the open group [16]. 
Fig. 3. Anatomical orientation in minimally invasive esophagectomy in prone position.
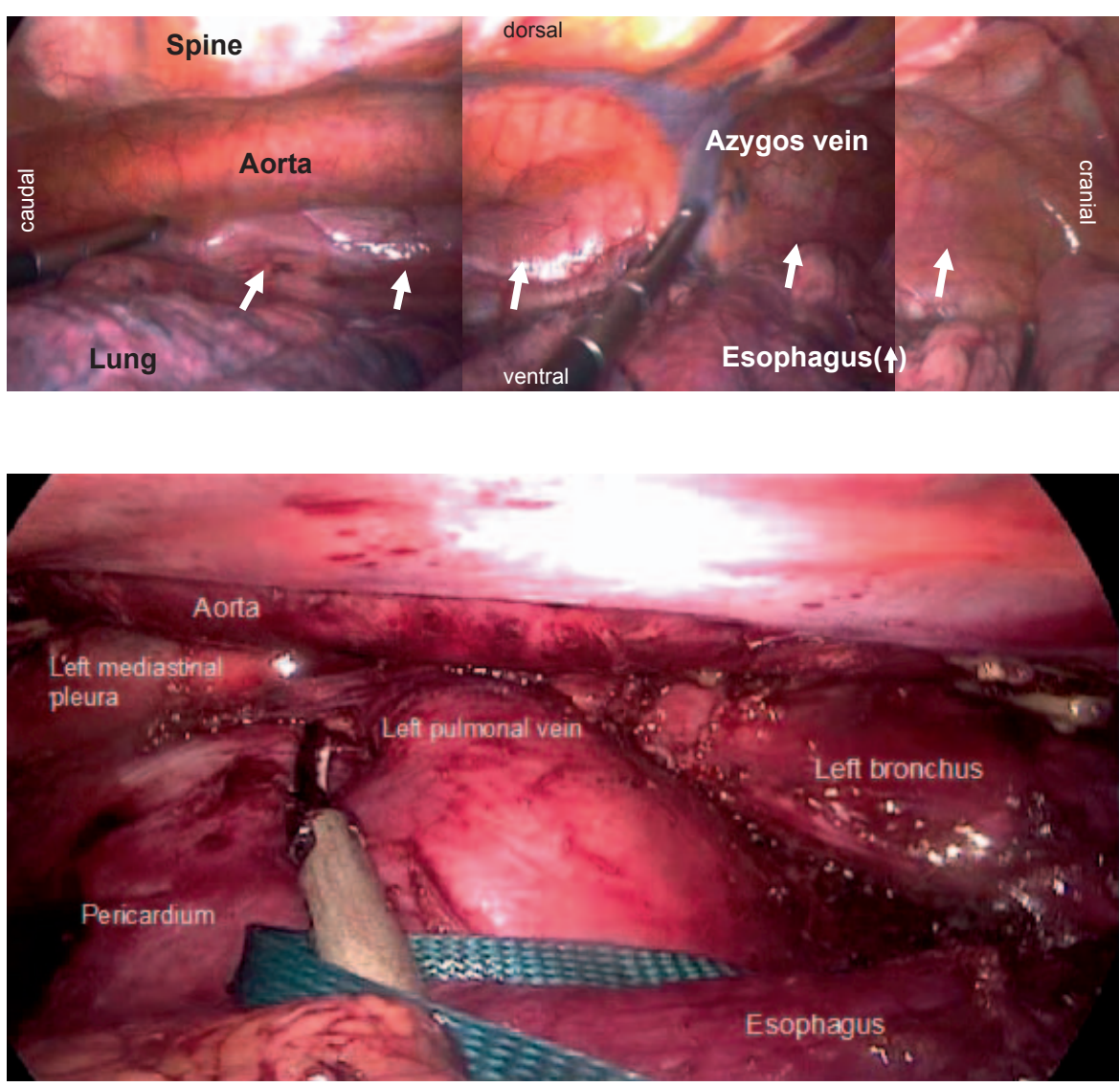

Extent of lymphadenectomy in the inferior mediastinum achieved during minimally invasive esophagectomy in prone position.

Table 1. Differences between left lateral decubitus position and prone position during minimally invasive esophagectomy

\begin{tabular}{lll}
\hline & Left lateral decubitus position & Prone position \\
\hline $\begin{array}{l}\text { One-lung ventilation } \\
\begin{array}{c}\text { Airway management/ability } \\
\text { performing bronchoscopy }\end{array}\end{array}$ & $\begin{array}{l}\text { necessary } \\
\text { easy }\end{array}$ & $\begin{array}{l}\text { sometimes helpful } \\
\text { more difficult }\end{array}$ \\
$\begin{array}{l}\text { Retraction of right lung } \\
\text { nuction of blood }\end{array}$ & $\begin{array}{l}\text { necessary } \\
\text { often necessary (blood pools } \\
\text { in the surgical field) }\end{array}$ & $\begin{array}{l}\text { not necessary } \\
\text { on occasion necessary (blood pools } \\
\text { ventral, outside the surgical field) }\end{array}$ \\
limited field of view, & good and stable overview, adaption \\
often situational adaption & to new anatomical perspective \\
necessary (retraction) & necessary \\
Emergency conversion & easy & more difficult \\
\hline
\end{tabular}

In 2010, Nagpal et al. [17] performed a meta-analysis and included twelve studies with a total of 672 patients in the cMIE and HMIE group as well as 612 patients in the OE group. This analysis showed a reduction in blood loss and pulmonary complications for cMIE and HMIE compared to OE. A reduction of stay on the intensive care unit (ICU) and of the length of hospital stay was seen only in cMIE patients but not in HMIE patients. Mortality did not differ between MIE and OE. The operative time was longer for cMIE [17].

To date, there is one prospective randomized multicenter trial in which a total of 115 patients were randomized (59 MIE, $56 \mathrm{OE}$ ). cMIE was performed with cervical anastomoses. In this trial, Biere et al. [18] showed a significantly reduced rate of pulmonary infections following cMIE compared to OE ( 9 vs. $29 \%, \mathrm{p}=0.005$ ), a re- duced blood loss (200 vs. $475 \mathrm{ml}, \mathrm{p}<0.001$ ), and reduced pain during the first 10 days postoperatively $(\mathrm{p}=0.001)$. The hospital mortality did not differ ( 2 vs. $3 \%$ ) as there were no differences in length of ICU stay and rate of anastomotic leakage. The operation took 30 min longer in the cMIE group $(\mathrm{p}=0.002)$. Vocal cord paralysis was less frequent in the cMIE group ( 2 vs. $14 \%, \mathrm{p}=0.012$ ). The trial included an analysis of the postoperative quality of life. 6 weeks after the operation, cMIE showed an improved postoperative quality of life compared to open surgery in a variety of dimensions [18].

In a population-based study, Mamidanna et al. [5] analyzed 7,502 esophagectomies performed in England between April 2005 and March 2010. In total, MIE amounted to $15.4 \%$. Morbidity and mortality did not differ between OE and MIE, as did length of hospital stay. MIE led to a reduction of $14 \%$ of postoperative respira- 
tory complications ( $\mathrm{p}=0.049$ ). Reinterventions ( 17.6 vs. $21 \%, \mathrm{p}=$ $0.006)$ and reoperations (5.6 vs. $8.8 \%, \mathrm{p}<0.001)$ were more frequent following MIE [5].

\section{Oncological Results}

Concerning a correct oncological resection, the number of harvested lymph nodes is often used as a surrogate parameter. The studies comparing the numbers of lymph nodes harvested in MIE compared to OE show that the clearance is at least equal in MIE. In their retrospective analyses, Osugi et al. [19] and Smithers et al. [20] reported an equal number of lymph nodes. Biere et al. [18] confirmed these results in a randomized trial.

In their recent systematic review, Dantoc et al. [21] found an increased number of harvested lymph nodes during MIE compared to OE (16 vs. $10, p=0.025$ ), without relevant differences between cMIE and HMIE.

The completeness of resection was analyzed in the randomized controlled trial from The Netherlands. The rate of R0 resection was $92 \%$ in CMIE and $84 \%$ in OE [18].

Burdall et al. [22] described a significant reduction of $\mathrm{R} 1$ resection in their retrospective analysis in cMIE patients. They found R1 resections amounting to $6.1 \%$ in cMIE, $20.3 \%$ in HMIE, and $15.6 \%$ in $\mathrm{OE}$ [22].

In view of long-term results, there has been no comparative study so far that suggested an unfavorable outcome after MIE. In 2003, Osugi et al. [19] reported comparable 3-year survival rates following HMIE and OE in patients which underwent three-field lymphadenectomy. Smithers et al. [20] described comparable 3 -year survival rates following two-field esophagectomies. A retrospective analysis from Taiwan found comparable stage-adjusted overall survival rates for both HMIE (VATS and laparotomy) and $\mathrm{OE}$ in squamous cell cancer. A trend towards a better disease-free survival after HMIE was shown in a multivariate analysis [23].

In a systematic review, Dantoc et al. [21] described comparable 3 -year survival rates but suggested an improved 1-year survival for MIE compared with OE (84.3 vs. $76.9 \%, \mathrm{p}=0.07$ ).

In a population-based analysis of 18,673 esophagectomies performed in England between 1996/1997 and 2007/2008, Lazzarino et al. [24] found a statistical trend towards increased 1-year survival following MIE when compared to $\mathrm{OE}$ (odds ratio $=0.68,95 \%$ confidence interval $=0.46-1.01, \mathrm{p}=0.058$ ).

\section{MIE versus HMIE}

In most reviews and meta-analyses, cMIE and HMIE are subsumed in one MIE group. A comparative analysis between HMIE and $\mathrm{OE}$ was published by Briez et al. [25]. Major postoperative pulmonary complications occurred significantly less after HMIE than after OE (15.7 vs. $42.9 \%, \mathrm{p}<0.001)$ [25].

The randomized controlled trial by Biere et al. [18] described above, the study by Luketich et al. [15] with more than 1,000 patients, and the multicenter trial from the USA [6] reflect the results of cMIE.

Kubo et al. [26] compared the results of 93 cMIE, 42 HMIE, and $74 \mathrm{OE}$. In this series, HMIE was performed by means of hand-assisted laparoscopy and thoracotomy. This study shows that cMIE led to a significant improvement $(\mathrm{p}<0.05)$ compared to OE regarding pulmonary complications, duration of systemic inflammatory response syndrome, and wound complications. cMIE showed a significantly higher occurrence of vocal cord palsy than OE and HMIE. Regarding HMIE the authors found no significant advantages over OE [26].

In a subgroup analysis, the population-based analysis of Mamidanna et al. [5] revealed a higher endoscopic reintervention rate following cMIE than HMIE (16.2 vs. 6.4\%, p < 0.001).

Palazzo et al. [27] performed a retrospective analysis comparing cMIE $(\mathrm{n}=104)$ versus OE combined with HMIE (OE: $\mathrm{n}=55$; HMIE: $\mathrm{n}=13$; sum-up in OE + HMIE: $\mathrm{n}=68)$. This group found a significant reduction of major morbidity in cMIE (19.2 vs. $44.1 \%$, $\mathrm{p}<0.01$ ), especially due to a reduction in pneumonia (6.7 vs. $20.5 \%$, $\mathrm{p}=0.01)$ and respiratory failure (15.4 vs. $30.8 \%, \mathrm{p}=0.03)$. Minor complications were more frequent in the cMIE group (37.5 vs. $22 \%$, $\mathrm{p}=0.05)$. The same analysis showed an improved 5 -year survival rate after cMIE compared to OE + HMIE (71.9 vs. $64.3 \%, \mathrm{p}<0.001)$. The analysis was adjusted for age, sex, total lymph nodes harvested, lymph node ratio, neoadjuvant therapy, and stage and hereupon showed a twofold greater risk of death after OE + HMIE than after cMIE (hazard ratio (HR) 2.00, 95\% CI 1.12-3.57, p = 0.019) [27].

Burdall et al. [22] have shown in a multivariate analysis that cMIE leads to improved long-term survival when compared to $\mathrm{OE}$ (HR 0.5186, $\mathrm{p}=0.0406$ ). In the same analysis, HMIE did not lead to a significantly improved long-term survival [22].

\section{Learning Curve}

There is a learning curve to be found in esophagectomy. Osugi et al. [28] described a reduction of operative time, a decrease in blood loss, an increased number of lymph nodes harvested, and a reduction of pulmonary complications after 34 patients.

Guo et al. [29] described a learning curve of 30 MIE with a significant improvement of operative time, blood loss, and number of retrieved lymph nodes. This group found further improvements in the next 30 patients concerning operative time and blood loss. A reduction of morbidity was found after 60 MIE [29].

Ramage et al. [30] observed a reduction of complications related to the gastric tube after 50 MIE cases.

The learning curve may be distinctly shortened with the help of an experienced instructor during the first cases [31].

\section{Discussion and Conclusion}

Since its introduction in 1994 the application of MIE is gradually increasing. Little is known about the regional distribution of MIE. In England, 24.7\% of esophagectomies were performed as MIE in 2009 , while the rate in Japan was $20 \%$ in the same year $[5,32]$.

The safety and feasibility of MIE has been demonstrated in several single-center studies, in one current multicenter phase II trial, and in a population-based analysis $[5,6,11,12,19]$.

To date, a number of single-center studies have demonstrated that MIE is associated with several advantages in short-term out- 
come known from other minimally invasive procedures. The published advantages include less blood loss, less pain, and less pulmonary morbidity.

These findings were supported by a meta-analysis, a few systematic reviews, and one randomized controlled trial [13, 17, 21].

While one single-center study did not find any reduction in pulmonary complications due to MIE [33], all other studies and the existing meta-analysis demonstrated that MIE leads to a significant reduction in pulmonary complications. The reduction ranged between $14 \%$ in the population-based analysis and $65 \%$ in a recent single-center analysis $[5,27]$. Whether the results of cMIE and HMIE are comparable in terms of pulmonary complications is somehow controversial. The reviews and the meta-analysis contain both techniques and do not list the results of cMIE and HMIE separately. The single-center study by Kubo et al. [26] addressed this question. This group found a significant reduction in the pulmonary complication rate after cMIE but not for HMIE, which included laparoscopy and thoracotomy [26]. In contrast, Briez et al. [25] described a significant reduction of major postoperative pulmonary complications following HMIE compared to OE. Nevertheless, the studies related to cMIE predominate. The large singlecenter studies by Luketich et al. [15] and Palanivelu et al. [12], the randomized controlled trial by Biere et al. [18], and the current multicenter trial from the USA [6] analyze cMIE patients. The evidence on cMIE is therefore more consistent and distinct than for HMIE.

A reduction of pulmonary complications is crucial in esophagectomy as these are known to be very frequent and to substantially increase the risk of perioperative death $[1,3]$.

Furthermore, postoperative pneumonia has been shown to have a negative impact on long-term survival following esophagectomy $[34,35]$.

The reduction of blood loss is another important benefit of MIE because an increased blood loss is associated with a negative influence on oncological outcome.

In colorectal surgery, blood transfusions are correlated with an increased risk of tumor recurrence [36]. In gastric surgery, blood transfusions have been shown to have a negative influence on longterm survival [37]. In esophagectomy, blood transfusions have also been identified as a negative factor regarding long-term survival [38, 39].

Apart from several advantages, cMIE may be associated with an increased risk of the necessity of postoperative endoscopic interventions, as shown by Mamidanna et al. [5] in their populationbased study. Other studies, especially the randomized controlled trial from The Netherlands, do not confirm these findings [17, 18, 20]. Nevertheless, this finding is noteworthy and brings the anastomosis even more into awareness while performing MIE.

The number of studies that address the question whether MIE is oncologically adequate is increasing. The rate of $\mathrm{R} 0$ resection is comparable between MIE and OE. Burdall et al. even found a lower $\mathrm{R} 1$ rate following cMIE $[18,22]$.

The number of lymph nodes has been repeatedly shown as adequate and comparable between cMIE, HMIE, and OE [18, 21]. Dantoc et al. [21] have stated an increased lymph node yield following cMIE and HMIE when compared to OE.

To date, all studies reporting long-term survival show very comparable results between MIE and OE [20, 23, 40]. The findings of Lazzarino et al. [24] in a population-based analysis suggest a better 1-year survival following MIE than after OE. Dantoc et al. [21] describe the same finding in their review from 2012. The long-term results of the randomized controlled trial from The Netherlands are going to provide more evidence regarding this aspect [18].

Although data are still somewhat limited and heterogeneous, cMIE and HMIE may be judged as safe, with advantages over OE in view of pulmonary complications. The current evidence is large enough for MIE/HMIE being included in the National Comprehensive Cancer Network (NCCN) guidelines in 2012, with an imminent inclusion in the forthcoming S3 guidelines in Germany.

\section{Disclosure Statement}

No conflicts of interest.

\section{References}

1 Hulscher JB, Van Sandick JW, de Boer AG, Wijnhoven BPL, Tijssen JGP, Fockens P, Stalmeier PFM, ten Kate FJW, van Dekken H, Obertrop H, Tilanus HW, van Lanschot JJB: Extended transthoracic resection compared with limited transhiatal resection for adenocarcinoma of the esophagus. N Engl J Med 2002;347:1662-1669.

2 Mariette C, Piessen G, Triboulet JP: Therapeutic strategies in oesophageal carcinoma: role of surgery and other modalities. Lancet Oncol 2007;8:545-553.

3 Atkins BZ, Shah AS, Hutcheson KA, Mangum JH, Pappas TH, Harpole DH Jr, D’Amico TA: Reducing hospital morbidity and mortality following esophagectomy. Ann Thorac Surg 2004;78:1170-1176.

4 Birkmeyer JD, Siewers AE, Finlayson EV, Stukel TA, Lucas FL, Batista I, Welch HG, Wennberg DE: Hospital volume and surgical mortality in the United States. N Engl J Med 2002;346:1128-1137.
5 Mamidanna R, Bottle A, Aylin P, Faiz O, Hanna GB: Short-term outcomes following open versus minimally invasive esophagectomy for cancer in England: a population-based national study. Ann Surg 2012;255:197203.

6 6 Luketich JD, Pennathur A, Franchetti Y, Catalano PJ, Swanson S, Sugarbaker DJ, De Hoyos A, Maddaus MA, Nguyen NT, Benson AIB, Fernando HC: Minimally invasive esophagectomy: results of a prospective phase II multicenter trial - the Eastern Cooperative Oncology Group (E2202) Study. Ann Surg 2015;261:702-707.

7 Cuschieri A, Shimi S, Banting S: Endoscopic oesophagectomy through a right thoracoscopic approach. J R Coll Surg Edinb 1992;37:7-11.

8 Collard JM, Lengele B, Otte JB, Kestens PJ: En-bloc and standard esophagectomies by thoracoscopy. Ann Thorac Surg 1993;56:675-679.
9 McAnena OJ, Rogers J, Williams NS: Right thoracoscopically assisted oesophagectomy for cancer. Br J Surg1994;81:236-238.

10 DePaula AL, Hashiba K, Ferreira EA, de Paula RA, Grecco E: Laparoscopic transhiatal esophagectomy with esophagogastroplasty. Surg Laparosc Endosc 1995;5:1-5.

11 Luketich J, Alvelo-Rivera M, Buenaventura P, Christie NA, McCaughan JS, Little VR, Schauer PR, Close JM, Fernando HC: Minimally invasive esophagectomy: outcomes in 222 patients. Ann Surg 2003;238:486-495.

12 Palanivelu C, Prakash A, Senthilkumar R, Senthilnathan P, Parthasarathi R, Rajan PS, Venkatachlam S: Minimally invasive esophagectomy: thoracoscopic mobilization of the esophagus and mediastinal lymphadenectomy in prone position - experience of $130 \mathrm{pa}$ tients. J Am Coll Surg 2006;203:7-16. 
13 Decker G, Coosemans W, De Leyn P, Decaluwe H, Nafteux P, van Raemdonk D, Lerut T: Minimally invasive esophagectomy for cancer. Eur J Cardiothorac Surg 2009;35:13-21.

14 Cuschieri A: Thoracoscopic subtotal oesophagectomy. Endosc Surg Allied Technol 1994;2:21-25.

15 Luketich JD, Pennathur A, Awais O, Levy RM, Keeley S, Shende M, Christie NA, Weksler B, Landreneau RJ, Abbas G, Schuchert MJ, Nason KS: Outcomes after minimally invasive esophagectomy, review of over 1000 patients. Ann Surg 2012;256:95-103.

16 Verhage RJJ, Hazebroek EJ, Boone J, van Hillegersberg R: Minimally invasive surgery compared to open procedures in esophagectomy for cancer: a systematic review of the literature. Minerva Chir 2009;64:135-146.

17 Nagpal K, Ahmed K, Vats A, Yakoub D, James D, Ashrafian H, Darzi A, Moorthy K, Athanasiou T: Is minimally invasive surgery beneficial in the management of esophageal cancer? A meta-analysis. Surg Endosc 2010;24:1621-1629.

18 Biere SS, van Berge Henegouwen MI, Maas KW, Bonavina L, Rosman C, Garcia JR, Gisbertz S, Klinkenbijl JHG, Hollmann MW, de Lange ESM, Bonjer HJ, van der Peet DL, Cuesta MA: Minimally invasive versus open oesophagectomy for patients with oesophageal cancer: a multicentre, open-label, randomised controlled trial. Lancet 2012;379:1887-1892.

19 Osugi H, Takemura M, Higashino M, Takada N, Lee S, Kinoshita H: A comparison of video-assisted thoracoscopic oesophagectomy and radical lymph node dissection for squamous cell cancer of the oesophagus with open operation. Br J Surg 2003;90:108-113.

20 Smithers BM, Gotley DC, Martin I, Thomas JM: Comparison of the outcomes between open and minimally invasive esophagectomy. Ann Surg 2007;245:232-240.

21 Dantoc MM, Cox MR, Eslick GD: Does minimally invasive esophagectomy (MIE) provide for comparable oncologic outcomes to open techniques? A systematic review. J Gastrointest Surg 2012;16:486-494.

22 Burdall OC, Boddy AP, Fullick J, Blazeby J, Krysztopik R, Streets C, Hollowood A, Barham CP, Titcomb D: A comparative study of survival after minimally invasive and open oesophagectomy. Surg Endosc 2015:29:431437.
3 Hsu PK, Huang CS, Wu YC, Chou TY, Hsu WH: Open versus thoracoscopic esophagectomy in patients with esophageal squamous cell carcinoma. World J Surg 2014;38:402-409

24 Lazzarino AI, Nagpal K, Bottle A, Faiz O, Moothy K, Aylin P: Open versus minimally invasive esophagectomy, trends of utilization and associated outcomes in England. Ann Surg 2010;252:292-298.

25 Briez N, Piessen G, Torres F, Lebuffe G, Triboulet JP, Mariette C: Effects of hybrid minimally invasive oesophagectomy on major postoperative pulmonary complications. Br J Surg 2012;99:1547-1553.

26 Kubo N, Ohira M, Yamashita Y, Sakurai K, Toyokawa T, Tanaka H, Muguruma K, Shibutani M, Yamazoe S, Kimura K, Nagahara H, Amano R, Ohtani H, Yashiro M, Maeda K, Hirakawa K: The impact of combined thoracoscopic and laparoscopic surgery on pulmonary complications after radical esophagectomy in patients with resectable esophageal cancer. Anticancer Res 2014;34:2399-2404.

27 Palazzo F, Rosato EL, Chaudhary A, Evans NR 3rd, Sendecki JA, Keith S, Chojnacki KA, Yeo CJ, Berger AC: Minimally invasive esophagectomy provides significant survival advantage compared with open or hybrid esophagectomy for patients with cancers of the esophagus and gastroesophageal junction. J Am Coll Surg 2015;220:672-679.

28 Osugi H, Takemura M, Higashino M, Takada N, Lee S, Ueno M, Tanaka Y, Fukuhara K, Hashimoto Y, Fujiwara Y, Kinoshita H: Learning curve of video-assisted thoracoscopic esophagectomy and extensive lymphadenectomy for squamous cell cancer of the thoracic esophagus and results. Surg Endosc 2003;17:515-519.

29 Guo W, Zou YB, Ma Z, Niu HJ, Jiang YG, Zhao YP, Gong TQ, Wang RW: One surgeon's learning curve for video-assisted thoracoscopic esophagectomy for esophageal cancer with the patient in lateral position: how many cases are needed to reach competence? Surg Endosc 2013;27:1346-1352.

30 Ramage L, Deguara J, Davies A, Hamouda A, Tsigritis K, Forshaw M, Botha AJ: Gastric tube necrosis following minimally invasive oesophagectomy is a learning curve issue. Ann R Coll Surg Engl 2013;95:329-334.
31 Ninomiya I, Osugi H, Tomizawa N, Fujimura T, Kayahara M, Takamura H, Fushida S, Oyama K, Nakagawara $\mathrm{H}$, Makino I, Ohta T: Learning of thoracoscopic radical esophagectomy: how can the learning curve be made short and flat? Dis Esophagus 2010;23:618-626.

32 Committee for Scientific Affairs; Sakata R, Fujii Y, Kuwano $\mathrm{H}$ : Thoracic and cardiovascular surgery in Japan during 2009: annual report by the Japanese Association for Thoracic Surgery. Gen Thorac Cardiovasc Surg 2011;59:636-667.

33 Safranek PM, Cubitt J, Booth MI, Dehn TCB: Review of open and minimal access approaches to oesophagectomy for cancer. Brit J Surg 2010;97:1845-1853.

34 Takeuchi H, Saikawa Y, Oyama T, Ozawa S, Suda K, Wada N, Takahashi T, Nakamura R, Shigematsu N, Ando N, Kitajima M, Kitagawa Y: Factors influencing the long-term survival in patients with esophageal cancer who underwent esophagectomy after chemoradiotherapy. World J Surg 2010;34:277-284.

35 Kinugasa S, Tachibana M, Yoshimura H, Ueda S, Fujii T, Dhar DK, Nakamoto T, Nagasue N: Postoperative pulmonary complications are associated with worse short- and long-term outcomes after extended esophagectomy. J Surg Oncol 2004;88:71-77.

36 Amato A, Pscatori M: Perioperative blood transfusions for the recurrence of colorectal cancer. Cochrane Database Syst Rev 2006;1:CD005033.

37 Liang YX, Guo HH, Deng JY, Wang BG, Ding XW, Wang XN, Zhang L, Liang H: Impact of intraoperative blood loss on survival after curative resection for gastric cancer. World J Gastroenterol 2013;19:5542-5550.

38 Langley SM, Alexiou C, Bailey DH, Weeden DF: The influence of perioperative blood transfusion on survival after esophageal resection for carcinoma. Ann Thorac Surg 2002;73:1704-1709.

39 Komatsu Y, Orita H, Sakurada M, Maekawa H, Hoppo $\mathrm{T}$, Sato K: Intraoperative blood transfusion contributes to decreased long-term survival of patients with esophageal cancer. World J Surg 2012;36:844-850.

40 Osugi H, Takemura M, Lee S, Nishikawa T, Fukuhara K, Iwasaki H, Higashino M: Thoracoscopic esophagectomy for intrathoracic esophageal cancer. Ann Thorac Cardiovasc Surg 2005;11:221-227. 